\title{
Good Response to Pemetrexed after Treatment Failure with Another Thymidylate Synthase Inhibitor in Lung Adenocarcinoma: A Case Report
}

\section{Fumihiko Hirai, Eiko Inamasu, Gouji Toyokawa, Tsukihisa Yoshida, Kaname Nosaki, Tomoyoshi Takenaka, Masafumi Yamaguchi, Mitsuhiro Takenoyama, Takashi Seto, Yukito Ichinose}

Department of Thoracic Oncology, National Kyushu Cancer Center, Fukuoka, Japan

Email: hirai.f@nk-cc.go.jp

Received 18 May 2014; revised 15 June 2014; accepted 8 July 2014

Copyright (C) 2014 by authors and Scientific Research Publishing Inc.

This work is licensed under the Creative Commons Attribution International License (CC BY).

http://creativecommons.org/licenses/by/4.0/

cc) (i)

\begin{abstract}
Pemetrexed is an antimetabolic agent and is well-known as a potent inhibitor of thymidylate synthase (TS). It also inhibits dihydrofolate reductase (DHFR) and glycinamide ribonucleotide formyl transferase (GARFT). We reported an intriguing case in which a non-small cell lung cancer patient who was refractory to pretreatment with S-1, a strong TS inhibitor, showed good response to pemetrexed treatment.
\end{abstract}

Keywords

Pemetrexed, S-1, Thymidylate Synthase

\section{Introduction}

Pemetrexed and S-1 are antitumor agents frequently used in patients with non-small cell lung cancer (NSCLC). The result of a phase III trial indicated the usefulness of pemetrexed as chemotherapy for patients with previously treated NSCLC [1]. Both of these are antimetabolic agents considered to inhibit mainlythymidylate synthase (TS). TS is essential for DNA synthesis and is one of the principal targets of anti-tumor treatment; however, a clear difference between these TS inhibitors has not been observed in clinical practice. We report an interesting case in which a NSCLC patient showed good response to pemetrexed even after progressive disease was observed following treatment with S-1.

How to cite this paper: Hirai, F., et al. (2014) Good Response to Pemetrexed after Treatment Failure with Another Thymidylate Synthase Inhibitor in Lung Adenocarcinoma: A Case Report. Journal of Cancer Therapy, 5, 766-768. 


\section{Case Report}

A 54-year-old woman presented with cough and sputum. Previously she had been diagnosed as having adenocarcinoma of the lung (cT4N3M0 stage IIIB) and received first-line chemotherapy with S-l (100 mg/body, d1-14) and cisplatin $\left(80 \mathrm{mg} / \mathrm{m}^{2}, \mathrm{~d} 1\right)$ on a three-week schedule [2]. After two cycles of this treatment, the tumor showed progressive disease.

About a month later she enrolled in a clinical trial in which second-line chemotherapy was started with pemetrexed $500 \mathrm{mg} / \mathrm{m}^{2}$ [3] [4]. The target lesion was located in the right upper lobe of the lung, and non-target lesions were observed in the left hilar lymph node, right hilar lymph node, and mediastinal lymph node. The patient also presented with lymphangitiscarcinomatosa (Figure 1(a)). Although there was no tumor response with S-1 and cisplatin therapy, partial response (PR) was observed after three cycles of treatment with pemetrexd, and continued for three cycles with the largest decrease in tumor size (40.0 mm to $9.5 \mathrm{~mm}$ : $76.2 \%$ reduction) seen in the right upper lobe after four cycles, as shown in Figure 1(b). After seven cycles, disease progression was observed and treatment was discontinued; progression-free survival (PFS) was 5.2 months. During this treatment, grade 3 neutropenia and leucopenia, which were possibly related to pemetrexed, were observed several times, but the patient recovered from all events. No serious adverse event was observed in this patient.

The patient was followed by other chemotherapies and died approximately 21 months after the first administration of pemetrexed.

\section{Discussion}

Single-agent chemotherapy with pemetrexed has been studied in previously treated patients in a Japanese phase II trial [3] [4]. Results from the randomized phase III trial showed a response rate of 9.1\% and median progression-free survival of 2.9 months. In the randomized Japan phase II trial, patients previously treated for locally advanced or metastatic non-small cell lung cancer were assigned to receive pemetrexed 500 or $1000 \mathrm{mg} / \mathrm{m}^{2}$. Results showed a response rate of 18.5\% (95\% Confidence Interval [CI]: 12.6\% - 25.8\%) with median progression-free survival of 3.0 months (95\% CI, $2.0-3.5$ months) in the $500 \mathrm{mg} / \mathrm{m}^{2}$ group.

This case was one of the 108 patients who were evaluable for efficacy in the $500 \mathrm{mg} / \mathrm{m}^{2}$ group of the phase II trial. She received seven cycles of pemetrexed treatment with severe adverse events. Even though this patient showed no response to previous treatment with S-1 plus cisplatin combination therapy, a remarkable response (76.2\% tumor reduction and progression-free survival of 5.2 months) was seen following treatment with pemetrexed. We feel that this notable difference in efficacy may have been due to differences in the mechanism of action between pemetrexed and S-1.

Both pemetrexed and S-1 are categorized as antimetabolic agents and strongly inhibit TS. However, these
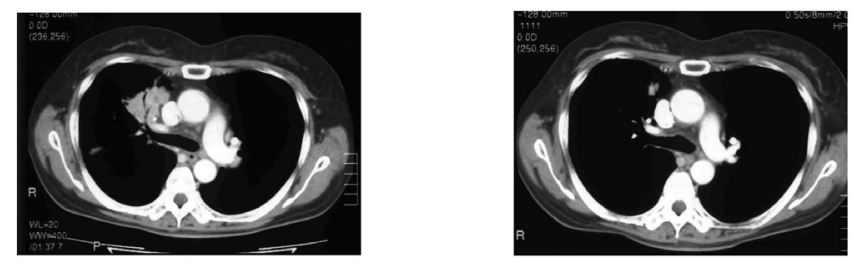

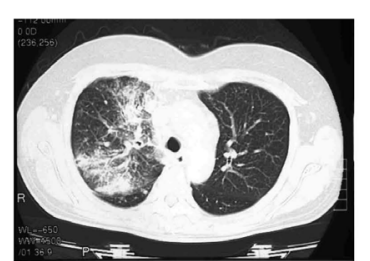

(a)

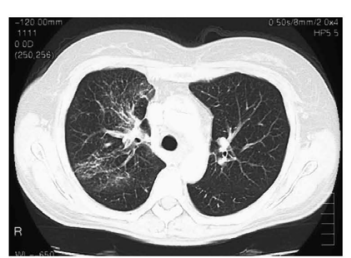

(b)

Figure 1. CT scan of the chest: right upper lobe (target lesion), lymphangitis carcinomatosa, and left hilar lymph nodes (above non-target lesions). (a) Before pemetrexed chemotherapy; (b) After four cycles ofpemetrexed chemotherapy, showing partial response in the target lesion. 
agents interact with two different TS substrate binding sites: one for deoxyuridine monophosphate (dUMP) and the other for the folate (5,10-methylenetetrahydrofolate polyglutamate). S-1 has three components: 5-Fluorouracil (5-FU) prodrug tegafur; 5-chloro-2, 4-dihydroxypyridine; and potassium oxonate. The 5-FU component is phosphorylated to 5-fluoro-2'-deoxyuridine 5'-monophosphate (FdUMP), which reacts with reduced folate cofactors to form a ternary complex with TS via interaction with dUMP binding site, thereby inhibiting pyrimidine synthesis. In contrast, pemetrexed, which is rapidly metabolized to active polyglutamate derivatives within cells, has a structure similar to that of folate. Pemetrexed inhibits pyrimidine synthesis by binding to TS instead of folate. Consequently, the interaction with TS is substantially different from that of S-1.

In addition, pemetrexed was shown to have a high inhibitory effect on dihydrofolate reductase (DHFR) and glycinamide ribonucleotide formyl transferase (GARFT) as well as TS in a previous preclinical research. It was reported that the Ki value of pemetrexed pentaglutamates was $1.3 \mathrm{nM}$ for TS inhibition, which may be comparable or superior to the reported Ki value of $6.4 \mathrm{nM}$ for 5-FU. Furthermore, pemetrexed pentaglutamates have also shown strong inhibition of DHFR and GARFT. The in vitro study has obtained Ki values of $7.2 \mathrm{nM}$ and 65 $\mathrm{nM}$, respectively, for each of these enzymes [5] [6]. Pemetrexed is a tight-binding inhibitor of several folatedependent enzymes and, as a result, inhibit pyrimidine/purine synthesis.

These differences in the mode of action may explain the clinical efficacy seen in this case. The response in this patient suggests that pemetrexed has a unique mode of action and is a potent multi-target antifolate agent in NSCLC.

\section{References}

[1] Hanna, N., Shepherd, F.A., Fossella, F.V., Pereira, J.R., De Marinis, F., von Pawel, J., Gatzemeier, U., Tsao, T.C., Pless, M., Muller, T., Lim, H.L., Desch, C., Szondy, K., Gervais, R., Shaharyar, Manegold, C., Paul, S., Paoletti, P., Einhorn, L. and Bunn Jr., P.A. (2004) Randomized Phase III Trial of Pemetrexed versus Docetaxel in Patients with Non-Small-Cell Lung Cancer Previously Treated with Chemotherapy. Journal of Clinical Oncology, 22, 1589-1597. http://dx.doi.org/10.1200/JCO.2004.08.163

[2] Kubota, K., Sakai, H., Yamamoto, N., Kunitoh, H., Nakagawa, K., Takeda, K., Ichinose, Y., Saijo, N., Ariyoshi, Y. and Fukuoka, M. (2010) A Multi-Institution Phase I/II Trial of Triweekly Regimen with S-1 plus Cisplatin in Patients with Advanced Non-Small Cell Lung Cancer. Journal of Thoracic Oncology, 5, 702-706.

[3] Ohe, Y., Ichinose, Y., Nakagawa, K., Tamura, T., Kubota, K., Yamamoto, N., Adachi, S., Nambu, Y., Fujimoto, T., Nishiwaki, Y., Saijo, N. and Fukuoka, M. (2008) Efficacy and Safety of Two Doses of Pemetrexed Supplemented with Folic Acid and Vitamin B12 in Previously Treated Patients with Non-Small Cell Lung Cancer. Clinical Cancer Research, 14, 4206-4212. http://dx.doi.org/10.1158/1078-0432.CCR-07-5143

[4] Kubota, K., Niho, S., Enatsu, S., Nambu, Y., Nishiwaki, Y., Saijo, N. and Fukuoka, M. (2009) Efficacy Differences of Pemetrexed by Histology in Pretreated Patients with Stage IIIB/IV Non-Small Cell Lung Cancer: Review of Results from an Open-Label Randomized Phase II Study. Journal of Thoracic Oncology, 4, 1530-1536. http://dx.doi.org/10.1097/JTO.0b013e3181b9e608

[5] Landis, D.M., Heindel, C.C. and Loeb, L.A. (2001) Creation and Characterization of 5-Fluorodeoxyuridine-Resistant Arg50 Loop Mutants of Human Thymidylate Synthase. Cancer Research, 61, 666-672.

[6] Shih, C., Chen, V.J., Gossett, L.S., Gates, S.B., MacKellar, W.C., Habeck, L.L., Shackelford, K.A., Mendelsohn, L.G., Soose, D.J., Patel, V.F., Andis, S.L., Bewley, J.R., Rayl, E.A., Moroson, B.A., Beardsley, G.P., Kohler, W., Ratnam, M. and Schultz, R.M. (1997) LY231514, a Pyrrolo[2,3-d]Pyrimidine-Based Antifolate That Inhibits Multiple FolateRequiring Enzymes. Cancer Research, 57, 1116-1123. 
Scientific Research Publishing (SCIRP) is one of the largest Open Access journal publishers. It is currently publishing more than 200 open access, online, peer-reviewed journals covering a wide range of academic disciplines. SCIRP serves the worldwide academic communities and contributes to the progress and application of science with its publication.

Other selected journals from SCIRP are listed as below. Submit your manuscript to us via either submit@scirp.org or Online Submission Portal.
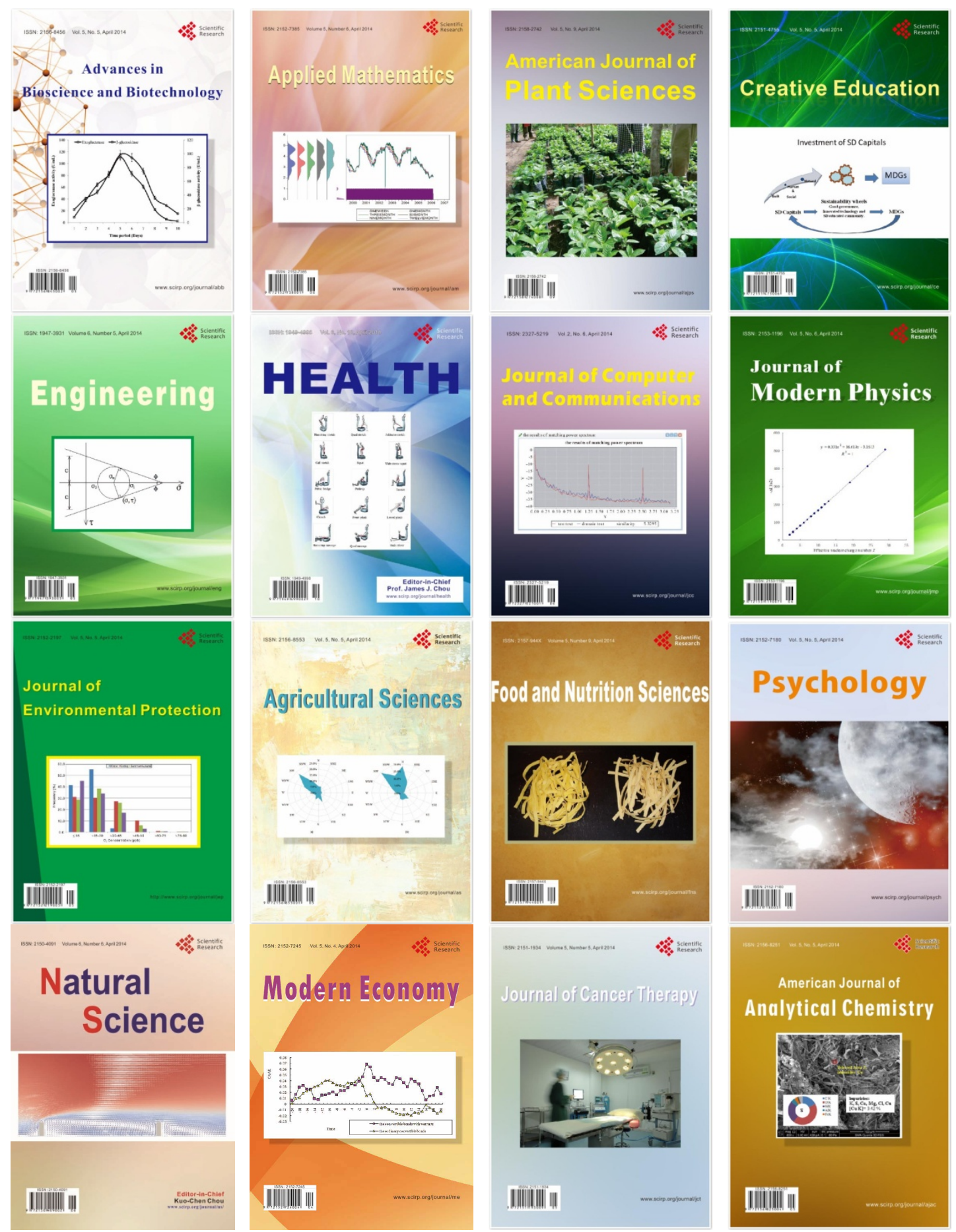